\title{
NASA intensifies probe into Columbia failure
}

\section{Tony Reichhardt, Washington}

"It's a detective story we are taking one piece at a time," says John Barry, a major general in the US air force and member of the board seeking the cause of the Columbia tragedy. But six weeks into the investigation, Barry and other board members admit that the reason why the space shuttle exploded on 1 February remains elusive.

At the same point after the 1986 Challenger disaster, investigators had already zeroed in on the cause. By contrast, those studying the break-up of Columbia are still collecting debris and running basic tests on the parts that could have failed.

Clues gleaned from flight data, recovered debris, and pictures and videos of the breakup have, however, allowed the investigators to construct a detailed timeline of the beginning and end of Columbia's last voyage.

Data from the booster rockets show that 62 seconds after launch, wind turbulence briefly exerted a stronger-than-usual force on the shuttle's left-hand side. Launch videos show that after a further 19 seconds, three pieces of what was probably the tank's foam insulation, but could have been foam mixed with ice, appeared to strike the leading edge of Columbia's left wing.

Investigators say that when the shuttle re-entered the atmosphere 15 days later, hot gases entered the left wing. These acted like a blowtorch, melting some of the aluminum frame and causing widespread damage.

But connecting the launch-day impact to those final events has not been straightforward. The debris struck several of 22 desksized panels of reinforced carbon insulation around the wing's leading edge. However, no panels are seen falling off Columbia in the launch videos, and the 200 or so pieces of the left wing recovered to date show no sign of having been hit by a large piece of debris. And wind-tunnel tests suggest that losing one of the panels would not be enough to destabilize the shuttle during re-entry.

Less obvious damage to the panels, or to the insulation that fills the gaps between them, may still be the culprit. Accident investigators have asked researchers at the Southwest Research Institute in San Antonio, Texas, to use high-speed guns to fire pieces of foam insulation at sections of insulation and supporting structure to characterize the kind of damage that this might cause.

The Wright-Patterson Air Force Base near Dayton, Ohio, is generating radar signatures for items such as heat-resistant tiles from the underside of the shuttle and pieces of carbon insulation. These will be compared with radar images of a mysterious object that was seen floating near the shuttle during its second day in space.

Staff at radar stations in southwestern

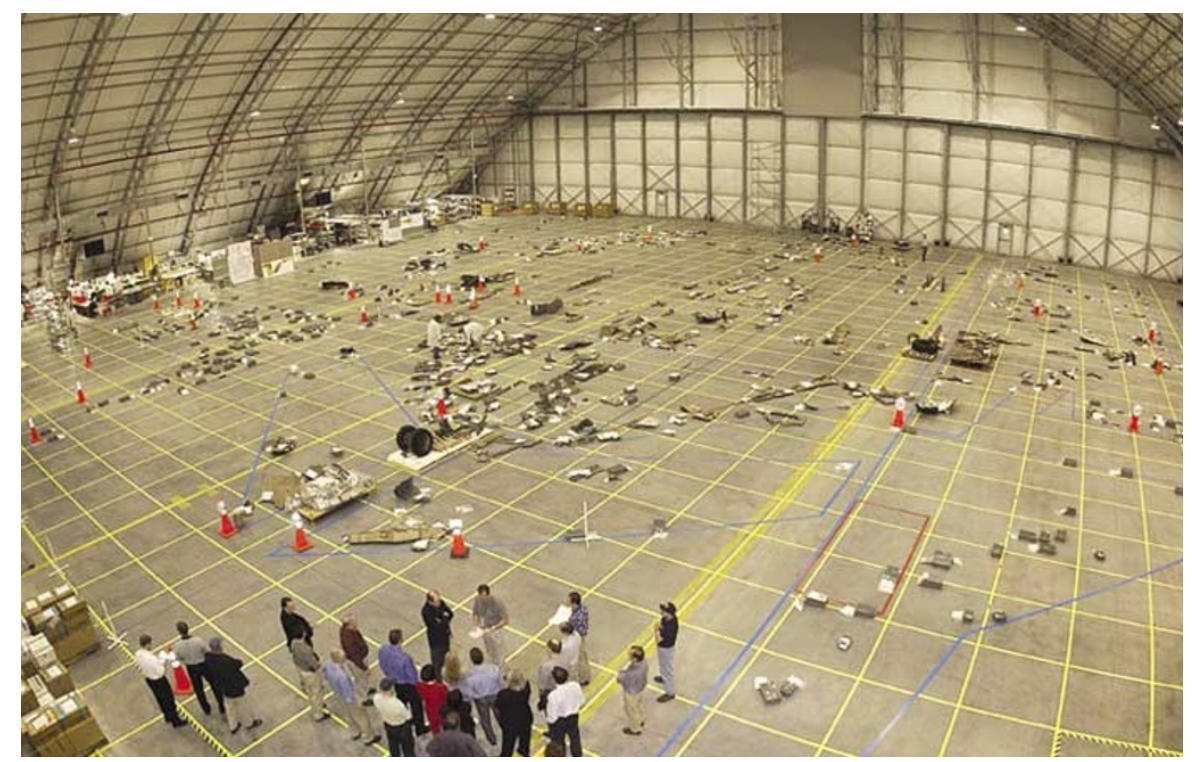

Accident investigators at the Kennedy Space Center piece together debris recovered from the shuttle.

states are also checking whether signals collected as Columbia flew overhead on its way to the landing strip at Kennedy Space Center in Florida might provide clues as to what went wrong. Ground-based images have shown that at least 16 pieces of debris were shed by the struggling vehicle as it sped over California, Arizona and New Mexico.

Board chairman Harold Gehman, a retired US Navy admiral, hopes to move soon from collecting information to a testing phase. Investigators are deciding what chemical and metallurgical tests to conduct on recovered debris to assess what damage they sustained. More than 28,000 pieces have been recovered to date. "Just laying them out on the floor is not enough," says Gehman.

The search for debris has cost $\$ 138$ million so far, with some 4,000 people and more than a dozen aircraft in the field every day. Twenty federal agencies are involved in the search, which will become more difficult in the coming weeks as spring comes to Texas, covering the main search area with foliage.

Meanwhile, NASA staff have begun work on plans to resume flying this year, perhaps as early as autumn. "The best therapy we can have is to be extremely engaged in solving this particular problem," said Ron Dittemore, manager of the space-shuttle programme, at a hearing earlier this month. The plans include reviewing methods for applying insulation to the shuttle's external fuel tank.

NASA administrator Sean O'Keefe said last week that the agency is not prejudging what Gehman's board will find, nor is it assuming that the shuttle will be cleared to fly this autumn. But NASA wants to do what it can now to address concerns that have already come up in the investigation. "The alternative is to sit here on our hands and wait for a report to be released," said O'Keefe.

\section{Alien-hunters get scope to search}

\section{John Whitfield}

The most promising results from the SETI@home search for extraterrestrial life are to be followed up using the world's largest radio telescope.

Since May 1999, SETI@home - run by the Search for Extra Terrestrial Intelligence, a non-profit organization - has divided radio signals from our Galaxy into quarter-megabyte chunks and sent them to the desktop computers of more than four million registered volunteers. The computers flag up strong or regular signals for subsequent analysis.
Later this month, researchers from the University of California will use the Arecibo telescope in Puerto Rico to study the locations indicated by the 150 most promising results. The project's chief scientist, Dan Werthimer of the University of California, Berkeley, says that there is about a 1-in-10,000 chance of finding something.

SETI staff say they could be looking at the wrong wavelengths or in the wrong place. "I'm optimistic that the Universe is teeming with life," says Werthimer. "But I'm not convinced we know exactly how to find it." http://setiathome.ssl.berkeley.edu 